\title{
In Vitro Treated Peripheral Blood Lymphocyte Therapy
}

National Cancer Institute

\section{Source}

National Cancer Institute. In Vitro Treated Peripheral Blood Lymphocyte Therapy. NCI

Thesaurus. Code C66900.

Any therapy in which peripheral blood lymphocytes are treated with a pharmacological agent and then transfused into a patient. 